\title{
Imiquimod 5\% Cream for an Annular Plaque with Progressive Pain on the Right Distal Arm in the Cubital Fossa: Acquired Tufted Angioma
}

\section{Jia Wang \\ Wen-Ying Chen}

Department of Comprehensive Ward, Zhejiang Hospital, Hangzhou, Zhejiang Province, 310013, People's Republic of China
Correspondence: Wen-Ying Chen Email cwy13357II@I63.com

\begin{abstract}
Tufted angioma, also known as angioblastoma, is a rare benign vascular neoplasm of the skin and subcutaneous tissue. The natural history of tufted angioma is slow, progressive growth for several years, and tends to remain stable thereafter, resulting in disfiguring appearance. The main choice of treatment for tufted angioma is complete surgical excision, but local recurrence is frequent. Here, we report a 33-year-old woman with a fouryear history of a steadily increasing pink to violaceous plaque on her right arm accompanied by spontaneous, progressive pain over the last seven months. Histology revealed multiple separated lobules of spindle cells throughout the dermis and subcutaneous tissue to the deep margin, with numerous mitoses but no cellular atypia, the small capillary-sized vessels scattered within the lobules, which were consistent with tufted angioma. To our satisfaction, her pain disappeared and the whole plaque was significantly improved after a four-month course of external application with imiquimod 5\% cream.
\end{abstract}

Keywords: tufted angioma, imiquimod, alternative therapy

\section{Introduction}

Acquired tufted angioma (TA) is a rare benign vascular condition first described as angioblastoma. ${ }^{1}$ Although it is entirely benign, extensive involvement is common and can result in disfiguring clinical appearance. ${ }^{1-3}$ Islands of clinically uninvolved skin within and around the tumor can be shown to be involved histologically, making surgical treatment difficult. Other treatment modalities have been tried with variable results, including radiation therapy, pulsed-dye laser, interferon- $\alpha$ and corticosteroids. ${ }^{1,4,5}$ Spontaneous regression has rarely been reported. ${ }^{6,7}$ We describe here a female patient presenting an annular plaque on the right distal arm in the cubital fossa with progressive pain which was diagnosed as acquired TA. In consideration of the annular appearance of the entity, surgical excision might not be suitable. In addition, imiquimod is supposed to have antiproliferative and apoptotic effects on vascular and lymphatic vessels and has a good curative efficacy in cutaneous lymphangioma and infantile hemangiomas, ${ }^{8-11}$ we tried imiquimod 5\% cream as an alternative therapy for her. To our surprise, her pain disappeared and the whole plaque was significantly improved after a four-month treatment of imiquimod $5 \%$ cream.

\section{Case Report}

A 33-year-old woman was referred with a four-year history of a steadily increasing pink to violaceous plaque on her right arm accompanied by 
spontaneous, progressive pain in the recent seven months. The lesion was becoming indurated slowly, but had never bled. On physical examination, an almost circumferential pink-colored plaque, $60 \times 80 \mathrm{~mm}$ in size, strong, but pliable in texture, was located on the right distal arm in the cubital fossa. The central part had a tendency of regression, with the periphery still enlarging (Figure 1A). The plaque was tender to palpation, and pain could occur in the night, which seriously affected her sleep. A biopsy was taken from the lesion, and histology revealed multiple separated lobules of spindle cells throughout the dermis and subcutaneous tissue to the deep margin, with numerous mitoses but no cellular atypia. Small capillary-sized vessels were scattered within the lobules (Figure 1B). These findings were consistent with tufted angioma. Complete blood cell count was also performed and revealed a normal platelet count, which excluded Kasabach-Merritt syndrome. Because imiquimod, an immunomodulator, is supposed to have antiproliferative and apoptotic effects on vascular and lymphatic vessels and has a good curative efficacy in cutaneous lymphangioma and infantile hemangiomas, ${ }^{8-11}$ we tried off-label use of imiquimod $5 \%$ cream for TA (three times per week). Surprisingly, this alternative therapy resulted in an excellent response, her pain was relieved after one week, and almost disappeared after one month without any analgesics, and the lesion was also gradually getting softer. She then continued the application frequency, and after four months, the whole plaque was significantly improved without any side effects (Figure 1C). The whole therapy was terminated thereafter. The patient reported no recurrence or pain during the next one year of follow-up.

\section{Discussion}

Tufted angioma is classified into congenital and acquired TA. It occurs equally in both sexes, arising more often between one and five years old, and may rarely develop at birth or in adulthood. ${ }^{1-3}$ The natural history of TA is slow, progressive growth for several years, and a tendency to remain stable thereafter. Spontaneous regression can be more likely to occur in younger patients and can take up to two years. ${ }^{7}$

TA is clinically featured by ill-defined, dull red-brownish or purple, angiomatous papules. Sometimes multiple papules and nodules may be superimposed on the main lesion. The lesions are mostly tender to palpation and may be associated with localized hypertrichosis. Histologically, there are numerous discrete lobules of capillaries set in the dermis and subcutis. The irregularly distributed lobules are composed of plump endothelial cells and spindle-shaped pericytes, and are tightly packed together, bulging into peripherally placed thinwalled semilunar vessels suggestive of lymphatics. There is no mitotic activity or cellular atypia. ${ }^{1,2}$

Dermoscopy is also helpful in the clinical diagnosis of TA. Dermoscopic features could be unique, with numerous tiny red lacunae separated by thin, whitish linear septa if the lesion was present throughout the dermis. Although red lacunae and linear septa can be seen in other hemangiomas, these TA components would be smaller than those of other hemangiomas because of the smaller units of each aggregate and connective tissue in TA. ${ }^{12}$

The gradually growing annular configuration with recent pain of the skin plaque on the arm in this patient makes it an atypical clinical feature, and it must be distinguished clinically from the lesions of lupus vulgaris, annular sarcoid, and granuloma annulare. The absence of granuloma, pallisaded histiocytes around a central mucinous collection, and narrow
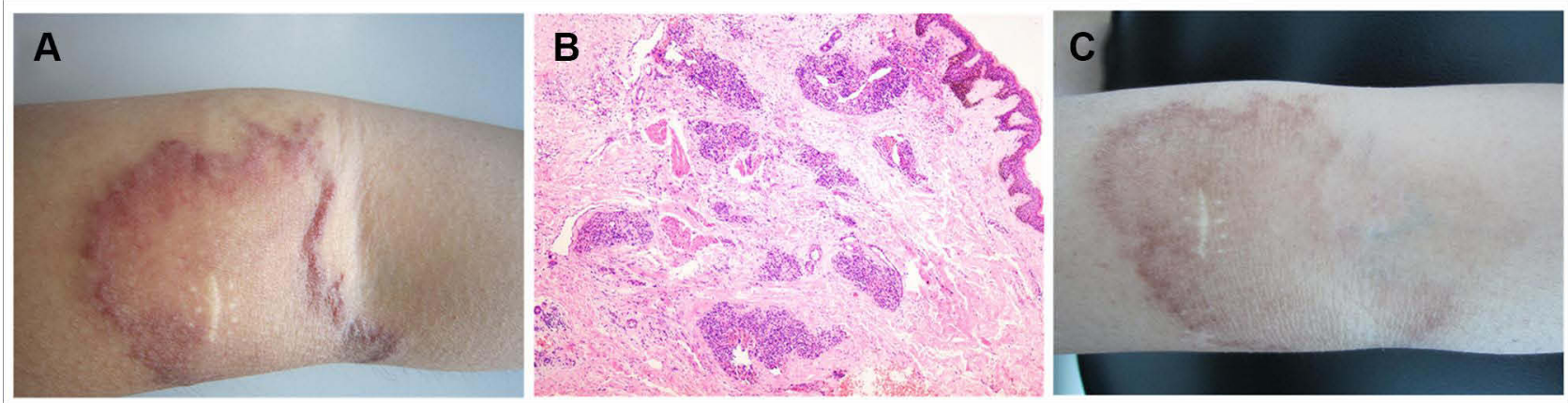

Figure I The clinical and pathological features of the lesion on the patient's arm. (A) The skin lesion located on the patient's right distal arm in the cubital fossa before any treatment; (B) The histology revealed numerous discrete lobules of capillaries set in the dermis. The lobules themselves are composed of multiple, bland, small, capillarysized vessels (hematoxylin and eosin staining, original magnification $\times 40$ ); (C) The skin lesion got significantly improved after a four-month course of treatment with imiquimod $5 \%$ cream. 
transepidermal channels with irregular elastic fiber can rule out these diseases. A more serious consideration is to differentiate vascular malignancies including Kaposi's sarcoma and angiosarcoma. Kaposi's sarcoma exhibits solid foci of spindle cells with varying degrees of atypia, separated by clefts containing red blood cells, often accompanied by hemosiderin granules and intracytoplasmic eosinophilic granules. Angiosarcoma shows, focally or extensively, the formation of anastomosing vascular channels lined by atypical endothelial cells, often surrounding and separating dermal collagen fibers. Therefore, an incisional biopsy is helpful in promoting recognition of this rare vascular tumor.

The treatment of choice for TA is complete surgical excision if the lesion is small enough, although local recurrence is frequent. ${ }^{2}$ Alternative treatment options include observation, soft X-ray and laser therapy, systemic use of corticosteroids and interferon- $\alpha .^{1,4,5,7}$ Previous experience has demonstrated that imiquimod has a good efficacy in treatment of cutaneous lymphangioma and infantile hemangiomas. ${ }^{8,9}$ The antiproliferative and apoptotic effects on vascular and lymphatic vessels were supposed to be the curative mechanism for imiquimod. ${ }^{10,11}$ So, we decided to try off-label use of imiquimod 5\% cream for TA in this patient. Surprisingly, as a result, her pain disappeared and the whole plaque was significantly improved without obvious side effects in an unexpectedly short period, which was shorter than that in reported cases of superficial infantile hemangioma whose regression occurred after approximately six weeks of treatment. The patient reported no recurrence or pain during the one year follow-up. To our knowledge, this is the first successful report to show positive effect of imiquimod in treatment of TA, offering an alternative therapy for the disease.

\section{Conclusion}

TA is a rare benign vascular entity, although surgical excision is the mainstream treatment currently, people are still seeking alternative treatment options because of frequent local recurrence and other reasons. Our study demonstrated external application of imiquimod 5\% cream as an efficacious, tolerable and invasive therapy for TA. The limitations of our report are that it is not a self-controlled trial, and it lacks pathological results after termination of therapy as a contrast. Also, if more patients could be enrolled, the result would be more convincing from a case series study.

\section{Data Sharing Statement}

The datasets supporting the conclusion of this article are included in the article.

\section{Ethics Statement}

Institutional approval was required to publish the case details.

\section{Consent to Publish}

Written informed consent was obtained from the patient, and she agreed to have the case details and any accompanying images published.

\section{Funding}

No sources of funding or support to be declared.

\section{Disclosure}

The authors report no conflicts of interest in this work.

\section{References}

1. Wilson Jones E, Orkin M. Tufted angioma (angioblastoma). A benign progressive angioma, not to be confused with Kaposi's sarcoma or low-grade angiosarcoma. J Am Acad Dermatol. 1989;20(2 Pt 1):214-225.

2. Vanhooteghem O, André J, Bruderer P, Touma D, Benkirane F, Song M. Tufted angioma, a particular form of angioma. Dermatology. 1997;194(4):402-404. doi:10.1159/000246161

3. Hebeda CL, Scheffer E, Starink TM. Tufted angioma of late onset. Histopatholog. 1993;23(2):191-199. doi:10.1111/j.1365-2559.1993. tb00481.x

4. Park KC, Ahn PS, Lee YS, Kim KH, Cho KH. Treatment of angioblastoma with recombinant interferon-alpha 2. Pediatr Dermatol. 1995;12(2):184-186. doi:10.1111/j.1525-1470.1995.tb00150.x

5. Padilla RS, Orkin M, Rosai J. Acquired 'tufted' angioma (progresive capillary hemangioma). A distinctive clinicopathologic entity related to lobular capillary hemangioma. Am J Dermatopathol. 1987;9 (4):292-300. doi:10.1097/00000372-198708000-00002

6. Miyamoto T, Mihara M, Mishima E, Hagari Y, Shimao S. Acquired tufted angioma showing spontaneous regression. $\mathrm{Br} J$ Dermatol. 1992;127(6):645-648. doi:10.1111/j.1365-2133.1992.tb14881.x

7. Ishikawa K, Hatano Y, Ichikawa H, Hashimoto H, Fujiwara S. The spontaneous regression of tufted angioma. A case of regression after two recurrences and a review of 27 cases reported in the literature. Dermatology. 2005;210(4):346-348. doi:10.1159/000084764

8. Mao XH, Wang JY, Yan JL. Topical imiquimod treatment of cutaneous vascular disorders in pediatric patients: clinical evaluation on the efficacy and safety. $J$ Zhejiang Univ Sci. 2012;13(9):745-750. doi:10.1631/jzus.B1200120

9. Wang JY, Liu LF, Mao XH. Treatment of lymphangioma circumscriptum with topical imiquimod 5\% cream. Dermatol Surg. 2012;38 (9):1566-1569. doi:10.1111/j.1524-4725.2012.02528.x

10. Kouba DJ, Yip D, Fincher EF, Moy RL. Topical imiquimod in the treatment of a long-standing capillary malformation. $\mathrm{Br}$ $J$ Dermatol. 2007;157(5):1071-1072. doi:10.1111/j.1365-2133.20 07.08181.x

11. Bongiorno MR, Aricò M. Preliminary communication: imiquimod in mixed capillary/lymphatic malformation. Dermatol Ther. 2008;21(Suppl 2):S39-42. doi:10.1111/j.1529-8019.2008.00 232. $\mathrm{x}$

12. Oya K, Nakamura Y, Fujisawa Y, et al. Tufted angioma of the finger: a case of an uncommon location with unique dermoscopic features. J Dermatol. 2018;45(8):e236-e237. doi:10.1111/1346-81 38.14279 


\section{Publish your work in this journal}

Clinical, Cosmetic and Investigational Dermatology is an international, peer-reviewed, open access, online journal that focuses on

the latest clinical and experimental research in all aspects of skin disease and cosmetic interventions. This journal is indexed on CAS.
The manuscript management system is completely online and includes a very quick and fair peer-review system, which is all easy to use. Visit http://www.dovepress.com/testimonials.php to read real quotes from published authors. 